\title{
Radiation belt electron precipitation into the atmosphere: Recovery from a geomagnetic storm
}

\author{
Craig J. Rodger, ${ }^{1}$ Mark A. Clilverd, ${ }^{2}$ Neil R. Thomson, ${ }^{1}$ Rory J. Gamble, ${ }^{1}$ \\ Annika Seppälä, ${ }^{3}$ Esa Turunen, ${ }^{4}$ Nigel P. Meredith, ${ }^{5}$ Michel Parrot, ${ }^{6}$ Jean-André Sauvaud, ${ }^{7}$ \\ and Jean-Jacques Berthelier ${ }^{8}$ \\ Received 4 March 2007; revised 5 June 2007; accepted 10 August 2007; published 16 November 2007.
}

[1] Large geomagnetic storms are associated with electron population changes in the outer radiation belt and the slot region, often leading to significant increases in the relativistic electron population. The increased population decays in part through the loss, that is, precipitation from the bounce loss cone, of highly energized electrons into the middle and upper atmosphere (30-90 km). However, direct satellite observations of energetic electrons in the bounce loss cone are very rare due to its small angular width. In this study we have analyzed ground-based subionospheric radio wave observations of electrons from the bounce loss cone at $L=3.2$ during and after a geomagnetic disturbance which occurred in September 2005. Relativistic electron precipitation into the atmosphere leads to large changes in observed subionospheric amplitudes. Satellite-observed energy spectra from the CRRES and DEMETER spacecraft were used as an input to an ionospheric chemistry and subionospheric propagation model, describing the ionospheric ionization modifications caused by precipitating electrons. We find that the peak precipitated fluxes of $>150 \mathrm{keV}$ electrons into the atmosphere were $3500 \pm 300 \mathrm{el} \mathrm{cm}^{-2} \mathrm{~s}^{-1}$ at midday and $185 \pm 15 \mathrm{el} \mathrm{cm}^{-2} \mathrm{~s}^{-1}$ at midnight. For $6 \mathrm{~d}$ following the storm onset the midday precipitated fluxes are approximately 20 times larger than observed at midnight, consistent with observed day/night patterns of plasmaspheric hiss intensities. The variation in DEMETER observed wave power at $L=3.2$ in the plasmaspheric hiss frequency band shows similar time variation to that seen in the precipitating particles. Consequently, plasmaspheric hiss with frequencies below $\sim 500 \mathrm{~Hz}$ appears to be the principal loss mechanism for energetic electrons in the inner zone of the outer radiation belts during the nonstorm time periods of this study, although off-equatorial chorus waves could contribute when the plasmapause is $L<3.0$.

Citation: Rodger, C. J., M. A. Clilverd, N. R. Thomson, R. J. Gamble, A. Seppälä, E. Turunen, N. P. Meredith, M. Parrot, J.-A. Sauvaud, and J.-J. Berthelier (2007), Radiation belt electron precipitation into the atmosphere: Recovery from a geomagnetic storm, J. Geophys. Res., 112, A11307, doi:10.1029/2007JA012383.

\section{Introduction}

[2] The behavior of high-energy electrons trapped in the Earth's Van Allen radiation belts has been extensively studied, through both experimental and theoretical techniques. During quiet times, energetic radiation belt electrons are distributed into two belts divided by the "electron slot"

\footnotetext{
${ }^{1}$ Department of Physics, University of Otago, Dunedin, New Zealand. ${ }^{2}$ Physical Sciences Division, British Antarctic Survey, Cambridge, UK. ${ }^{3}$ Finnish Meteorological Institute, Helsinki, Finland.

${ }^{4}$ Sodankylä Geophysical Observatory, Sodankylä, Finland.

${ }^{5}$ Physical Sciences Division, British Antarctic Survey, Cambridge, UK.

${ }^{6}$ Laboratoire de Physique et Chimie de l'Environnement, Orleans, France.

${ }^{7}$ Centre d'Etude Spatiale des Rayonnements, Toulouse, France.

${ }^{8}$ Centre d'Etudes des Environnements Terrestre et Planétaires, Saint Maur des Fosses, France.

Copyright 2007 by the American Geophysical Union. 0148-0227/07/2007JA012383
}

at $L \sim 2.5$. In the more than 4 decades since the discovery of the belts [Van Allen, 1997], it has proved difficult to confirm the principal source and loss mechanisms that control radiation belt particles [Walt, 1996]. It has been recognized for some time that the loss of radiation belt electrons in the inner magnetosphere is probably dominated by both pitch angle scattering in wave-particle interactions with whistler mode waves and Coulomb scattering. Collisions with neutral atmospheric constituents are the dominant loss process for energetic electrons $(>100 \mathrm{keV})$ only in the innermost parts of the radiation belts $(L<1.3)$ [Walt, 1996], as demonstrated by the comparison of calculated decay rates with the observed loss of electrons injected by the 1962 Starfish nuclear weapon test [Walt, 1994, Figure 7.3]. For higher $L$-shells, radiation belt particle lifetimes are many orders of magnitude shorter than those predicted from atmospheric collisions, such that other loss processes are clearly dominant. Above $L \sim 1.5$, Coulomb collisiondriven losses are generally less important than those driven 
by whistler mode waves, including plasmaspheric hiss, lightning-generated whistlers, and manmade transmissions [Abel and Thorne, 1998]. The electron slot is believed to result from enhanced electron loss rates occurring in this region. Much attention has been given to the role of plasmaspheric hiss in maintaining the electron slot [Lyons and Williams, 1984], although it has been suggested that lightning-generated whistlers may also be significant in this region [e.g., Lauben et al., 2001]. Other calculations suggest that all three types of whistler mode waves may play important roles in the loss of energetic electrons in the inner magnetosphere [Abel and Thorne, 1998].

[3] Relatively small changes in the outflow of particles from the Sun can trigger geomagnetic storms [Sharma et al., 2004], which produce large changes in radiation belt populations. Typically, the relativistic electron population drops out during the main phase of a storm, recovering on a timescale of $\sim 1 \mathrm{~d}$ to a level that may or may not be greater than the prestorm level (but can be several orders of magnitude larger). Essentially, all geomagnetic storms substantially alter the electron radiation belt populations [Reeves et al., 2003], in which precipitation losses play a major role [Green et al., 2004]. A significant fraction of the particles are lost into the atmosphere [Horne, 2002; Friedel et al., 2002; Clilverd et al., 2006a], although storm-time nonadiabatic magnetic field changes also led to losses through magnetopause shadowing [e.g., Ukhorskiy et al., 2006].

[4] Large geomagnetic storms are associated with radiation belt electron population changes in the outer radiation belt, the electron slot region, and in rare cases the inner radiation belt $(L<2)$ [Baker et al., 2004], where lifetimes are extremely large and hence the increases are long-lived. An example of this was provided by SAMPEX satellite observations of relativistic electrons during a series of large storms that took place in October-November 2003 which show that the normal peak of electron fluxes around $L \approx 4.0$ was displaced far inward to $L<2.5$ for a period of at least two weeks. The period between 29 October and 4 November 2003, widely known as the Halloween storms, lead to a $10^{4}$ increase in relativistic electron population in the slot region [Baker et al., 2004]. This period was also associated with a number of "anomalies" in spacecraft in Earth orbit and beyond, and in some cases, failures [Webb and Allen, 2004]. It has been suggested that the very large and rapid increases in trapped electron populations provide strong evidence for acceleration processes driven by very low frequency (VLF) whistler mode chorus [Horne et al., 2005].

[5] The new population of 2-6 MeV electrons observed during two injections into the slot region at $L \approx 2.5$ decayed in an exponential manner, with e-folding lifetimes of 4.6 and $2.9 \mathrm{~d}$. However, owing to the very large increases in the $2-6 \mathrm{MeV}$ electron fluxes at $L \approx 2.5$ and the two injections which occurred in this period, the fluxes in the slot did not return to normal until 3-4 weeks after the second injection [Baker et al., 2004]. It is generally understood that the exponential loss was due to cyclotron resonant interactions with VLF waves near the equatorial zone [Tsurutani and Lakhina, 1997]. Pitch angle scattering of energetic radiation belt electrons [Kennel and Petschek, 1966] by whistler mode waves drives some resonant electrons into the bounce loss cone, resulting in their precipitation into the atmo- sphere. Direct satellite observations of energetic electrons in the bounce loss cone are very rare. For most of the outer radiation belts, the loss cone is too narrow to be clearly resolved by existing satellite-borne particle detectors.

[6] The effect of "pumping up" the radiation belts is eventually translated to the Earth by the loss, that is, precipitation, of highly energized electrons into the middle and upper atmosphere $(30-90 \mathrm{~km})$. The precipitation of energetic electrons changes the atmospheric radiation balance through the production of ozone destroying species which, in turn, modify climate forcing [Haigh et al., 2005]. Energetic electron precipitation results in enhancement of odd nitrogen $\left(\mathrm{NO}_{\mathrm{x}}\right)$ and odd hydrogen $\left(\mathrm{HO}_{\mathrm{x}}\right)$, which play a key role in the ozone balance of the middle atmosphere because they destroy odd oxygen through catalytic reactions [Brasseur and Solomon, 1986]. When this precipitation occurs during the winter darkness, the long-lived $\mathrm{NO}_{\mathrm{x}}$ produced is confined by the polar vortex, and within it descends downward to stratospheric altitudes throughout the winter [Callis et al., 1996; A. Seppälä et al., $\mathrm{NO}_{\mathrm{x}}$ enhancements in the middle atmosphere: Relative significance of solar proton events and the aurora as a source, submitted to Journal of Geophysical Research, 2007]; according to recent model results the following ozone reductions in the stratosphere lead to changes in temperature and could possibly effect atmospheric circulation as well as the variation in the zonal winds (QBO, quasi biennal oscillation) [Elias and de Artigas, 2003; Rozanov et al., 2005; Langematz et al., 2005].

[7] For electrons $>100 \mathrm{keV}$, the bulk of the precipitated energy is deposited into the middle and upper atmospheric levels $(\sim 30-90 \mathrm{~km})$ and hence causes the lower ionospheric boundary (the $D$ region), to shift downward. One of the few experimental techniques which can probe these altitudes uses VLF electromagnetic radiation, trapped between the lower ionosphere and the Earth [Barr et al., 2000]. The nature of the received radio waves is largely determined by propagation between these boundaries [e.g., Cummer, 2000]. Significant variations in the received amplitude and/or phase of fixed frequency VLF transmissions arise from changes in the lower ionosphere, for example, the additional ionization produced by energetic particle precipitation. VLF radio wave propagation has been shown to be sensitive to relativistic electron precipitation events during geomagnetic disturbances [Thorne and Larsen, 1976; Clilverd et al., 2006a]. The effect on the signals can be either an increase or decrease in signal amplitude, depending on the modal mixture of each signal observed. Further discussion on the use of subionospheric VLF propagation as a remote sensing probe can be found in recent review articles [e.g., Barr et al., 2000; Rodger, 2003]. Observations of subionospheric VLF transmissions permit observers to study energetic particle precipitation from locations remote from the actual precipitation region.

[8] In this study we analyze ground-based measurements of ionospheric ionization changes observed during and after a geomagnetic disturbance which occurred in September 2005. This geomagnetic disturbance led to increases in the electron fluxes in the slot and inner edge of the outer radiation belt. Our subionospheric radio wave observations show that while energetic protons from a solar proton event strike the high-latitude polar atmosphere, there is also 

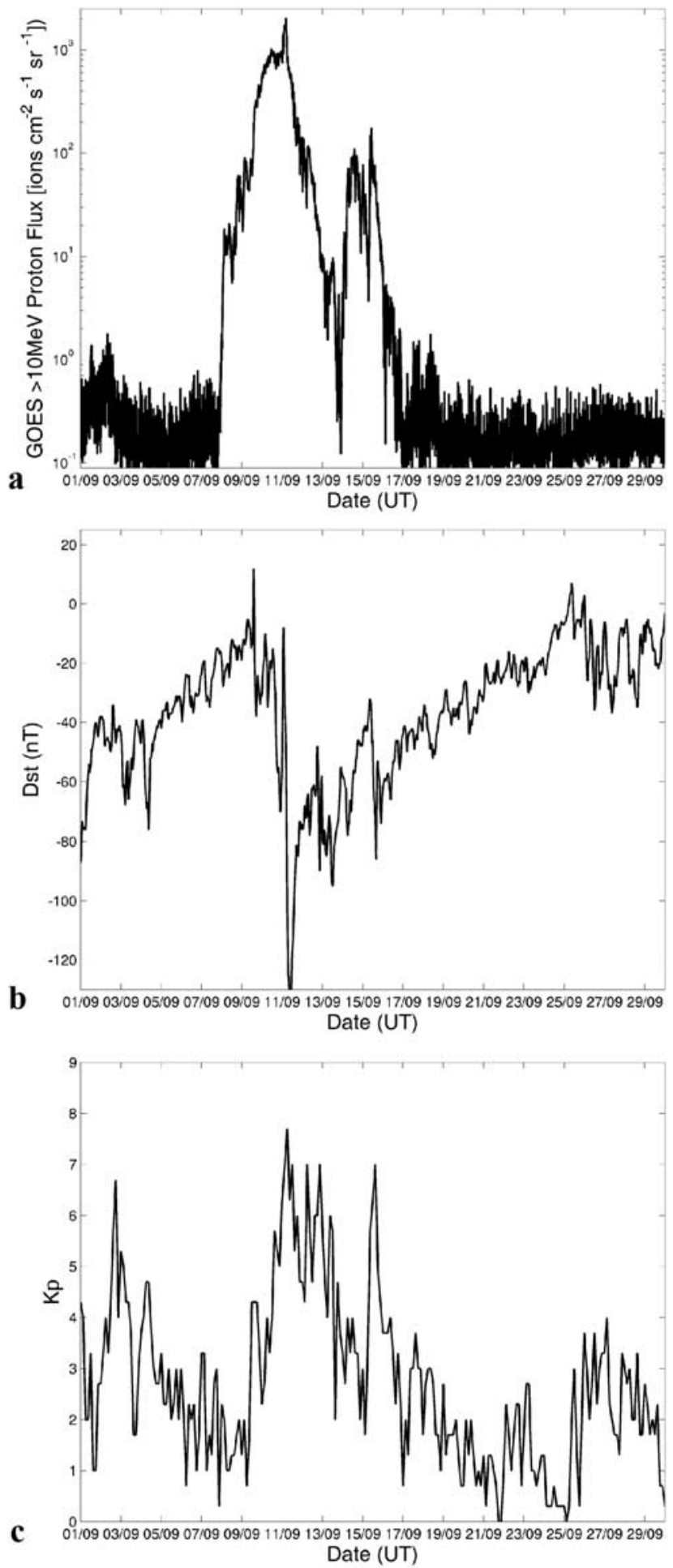

Figure 1. Summary of geophysical conditions appropriate for this study, starting from 1 September 2005, showing (a) the GOES-measured proton fluxes, (b) the $D_{s t}$ index, and (c) the $K_{p}$ index. relativistic electron precipitation occurring at $L \approx 3$. This highly energetic electron precipitation leads to large changes in subionospheric amplitudes, for both daytime and nighttime conditions. Measurements of electron fluxes are provided by instruments on board the Combined Release and Radiation Effects Satellite (CRRES) and DEMETER satellites, describing the changes in flux and energy spectrum. The observed energy spectra are used as an input to an ionospheric chemistry and subionospheric propagation model, to describe the nature of the ionosphere modified by precipitating electrons from the radiation belts. The combination of satellite and subionospheric measurements allows us to determine the time-varying electron precipitation fluxes into the atmosphere following a storm time injection into the inner edge of the outer radiation belt.

\section{Geophysical Conditions}

\subsection{Summary of Activity}

[9] In August-September 2005 there were a series of three major geomagnetic disturbances as recorded by the $D_{s t}$ index, each one of which was associated with a $>10$ times increase in the solar wind density and coronal mass ejections from the Sun. We focus on the last of the three disturbances due to subionospheric data we have available, as outlined in the section below. On 7 September 2005 the GOES spacecraft recorded an X17 solar flare which produced a solar proton event at the Earth shortly afterward. Proton fluxes at GOES orbits were increased for about a week. The X17 flare was followed over the next week by a series of flares, some of which were also greater than X1. During this time a GOES-detected X6.2 flare was associated with a SOHO reported "Halo" coronal mass ejection (CME) on 9 September 2005, with subsequent "Halo" CMEs on the 10th and 11th of September. This disturbed time period triggered a geomagnetic storm on 11 September 2005 , with $D_{s t}$ reaching $-120 \mathrm{nT}$ and $K_{p}$ reaching 8. A summary of the geophysical conditions from 1 September 2005 is shown in Figure 1. The top panel shows the GOESmeasured proton fluxes, the middle panel shows the $D_{s t}$ index, and the lower panel shows the $K_{p}$ index. This plot shows the time delay between the solar proton event seen in the upper panel, associated with a Halo CME launched from the Sun and a solar flare, and the geomagnetic storm seen in the lower two panels triggered by the arrival of the $\mathrm{CME}$ at the Earth.

\subsection{Satellite Observations of the Radiation Belts}

[10] The geomagnetic storm of 11 September 2005 led to an increase in the energetic electron population in the inner edge of the outer radiation belt. Figure 2 shows the evolution with time in satellite measured $>150 \mathrm{keV}$ integral electron flux at $L=3.2$ in the drift loss cone, observed by the IDP instrument onboard the DEMETER satellite. We do not include flux measurements made inside the South Atlantic Magnetic Anomaly. DEMETER is the first of the Myriade series of microsatellites developed by the Centre National d'Etudes Spatiales for low-cost science missions, and was placed in a circular Sun-synchronous polar orbit at an altitude of $710 \mathrm{~km}$ at the end of June 2004. The IDP spectrometer [Sauvaud et al., 2006] is unusual in that it has very high-energy resolution; in normal "survey" mode the 


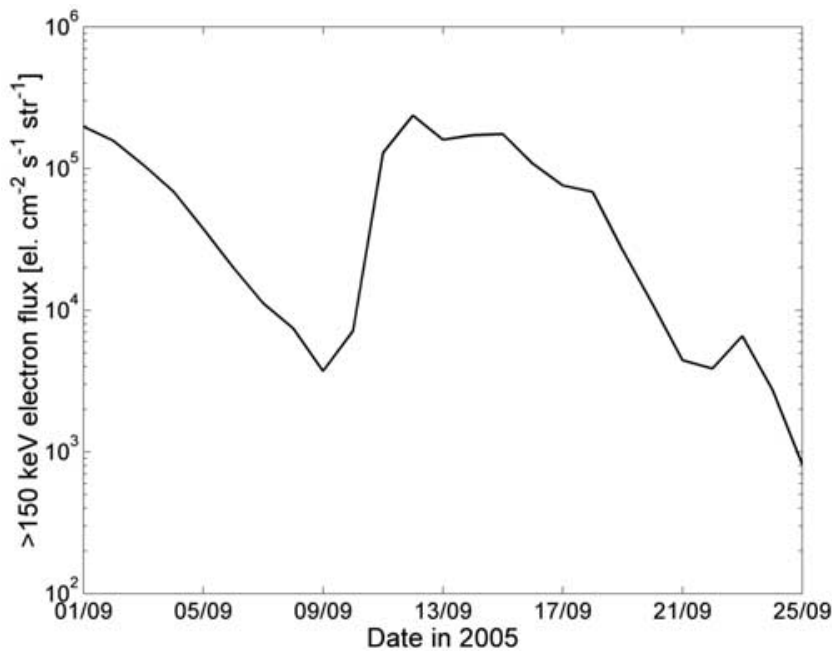

Figure 2. Variation with time of the $>150 \mathrm{keV}$ electrons at $L=3.2$ observed in the drift loss cone by the DEMETER spacecraft.

instrument measures electron fluxes in the drift loss cone with energies from $70 \mathrm{keV}$ to $2.34 \mathrm{MeV}$ using 128 energy channels. DEMETER observations at $L=3.2$ indicate that the typical $>150 \mathrm{keV}$ integral electron flux in the drift loss cone is $\sim 2 \times 10^{2}$ el. $\mathrm{cm}^{-2} \mathrm{~s}^{-1} \mathrm{sr}^{-1}$ which occurs outside the time range shown in this figure. Geomagnetic storms in late August 2005 boost the $>150 \mathrm{keV}$ fluxes to $\sim 2 \times 10^{5} \mathrm{el} . \mathrm{cm}^{-2} \mathrm{~s}^{-1} \mathrm{sr}^{-1}$, after which it decays as seen in Figure 2 in early September. After the 11 September 2005 geomagnetic storm DEMETER shows that the electron fluxes in the drift loss cone increases by a factor of $\sim 1000$ above ambient conditions and a factor of 100 above the prestorm flux levels. The fluxes decay to within a factor of 5 of the ambient levels/ noise floor over 14 days, after which there is a large data gap in the DEMETER data (several weeks).

[11] The DEMETER observations are consistent with the typical behavior of energetic electron increases at $L=3.05$ reported by CRRES. There were five events during the CRRES mission that resulted in perpendicular fluxes of $1.09 \mathrm{MeV}$ electrons greater than $1000 \mathrm{~cm}^{-2} \mathrm{~s}^{-1} \mathrm{sr}^{-1} \mathrm{keV}^{-1}$ at $L=3.05$. After each event the fluxes decayed gradually on a timescale of $\sim 5.5$ days either to quiet time levels or until another flux increase, all increases being caused by enhanced magnetic activity [Meredith et al., 2006a]. Unlike DEMETER, which measures electrons in the drift loss cone and is in low Earth orbit, CRRES was placed on a highly elliptical geosynchronous transfer orbit with a perigee of $305 \mathrm{~km}$ and an apogee of $35,768 \mathrm{~km}$, sweeping through the heart of the radiation belts approximately 5 times per day on average, and thus measuring trapped fluxes near the geomagnetic equator. For this reason we cannot make a "like with like" comparison between the measurements of the two spacecraft. The relatively long lifetime of CRRES, providing multiple energy channel observations of energetic radiation belt electrons, allows an indication of "typical" storm time increases and their subsequent decay to normal levels. However, CRRES was launched on 25 July 1990 and operated for 15 months and thus cannot provide direct observations for the disturbance in mid-September 2005.

[12] Figure 3 shows an example of the typical perpendicular electron flux spectra reported by the Medium Electrons A (MEA) experiment onboard CRRES following enhanced magnetic activity. The MEA instrument, which used momentum analysis in a solenoidal field, had 17 energy channels ranging from $153 \mathrm{keV}$ to $1.582 \mathrm{MeV}$ [Vampola et al., 1992]. This particular example is from 20 June 1991, following a geomagnetic storm which occurred on 17 June. The figure shows the trapped electron flux spectra for the 17 MEA energy channels. Also shown is a power-law fit to this flux spectrum (gray line), used to extend the energy range when considering the atmospheric precipitation as outlined below. The power law fit is in the form of $10^{-\gamma E}$ where $\gamma=1.2 \times 10^{-3} \mathrm{keV}^{-1}$. The thin line in Figure 3 shows the comparison with the DEMETER-observed spectrum for electrons in the drift loss cone at $L=3.2$ on 12 September 2005 , where the flux values have been shifted upward by a factor of 60 to overlay with the CRRES fluxes. The crosses indicate the energy channels and emphasize the difference between the two instruments' energy resolution. There is a very good agreement between the typical CRRES poststorm trapped flux spectrum and the energy spectrum reported by DEMETER in the drift loss cone across all energies. CRRES measured trapped fluxes about the geomagnetic equator, while DEMETER fluxes describe the drift loss cone. While neither instrument provides direct measurements of the particles precipitating in a specific part of the world, the agreement between the two provides strong evidence that this spectrum will provide a reasonable description of that in the bounce loss cone precipitating into the atmosphere and measured by our ground-based instruments. On the basis of Figure 3 we therefore make use of the fitted energy spectrum and the associated trapped

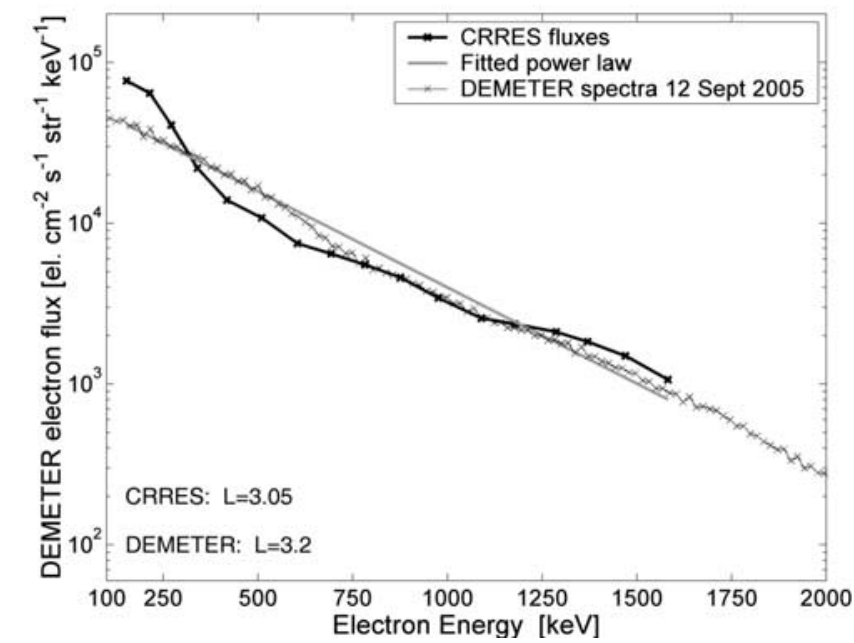

Figure 3. Electron energy spectra at $L \approx 3$, typical of those seen following significant enhanced magnetic activity leading to enhanced trapped electron fluxes. The heavy line shows the trapped flux measurements by CRRES, with the gray line indicating a power law fitting. The thin line shows the contrast with the DEMETER-observed spectra in the drift loss cone, shifted to overlay with the CRRES fluxes. 


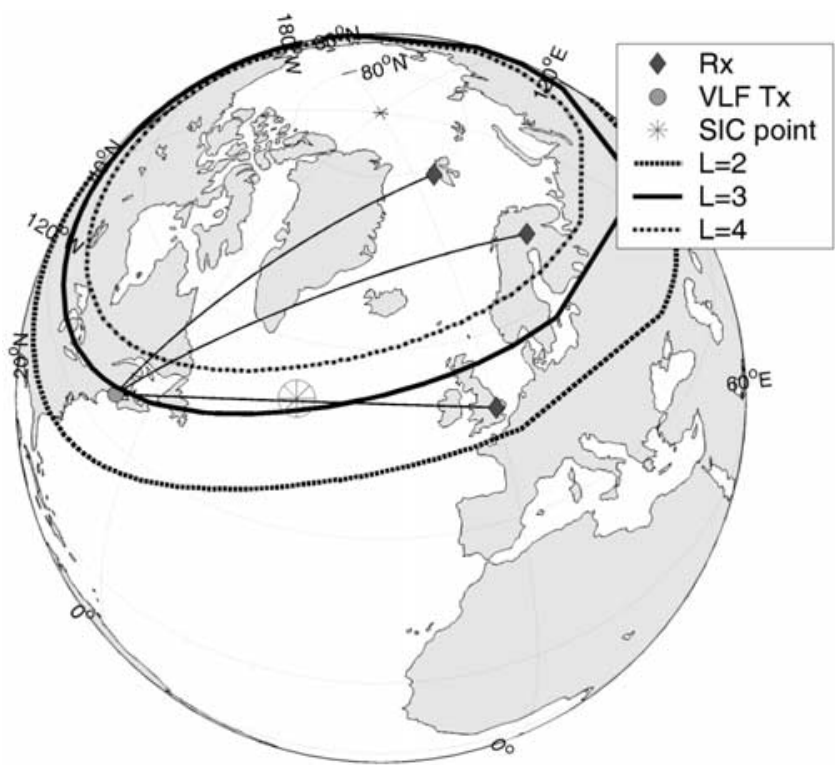

Figure 4. Map showing the location of the transmitter NAA, the VLF receivers (diamonds), and the modeling location. This map also indicates the great circle propagation paths between the transmitter and receivers.

CRRES magnitudes to determine the magnitude of the energetic precipitation into the atmosphere during the midSeptember 2005 period.

\section{Subionospheric Experimental Observations}

\subsection{Experimental Setup}

[13] Here we use narrow band subionospheric VLF data from a $24.0 \mathrm{kHz}$ transmitter (call sign NAA, $44.6^{\circ} \mathrm{N}$, $67.3^{\circ} \mathrm{W}, L=3$ ) located in Cutler, Maine and received at three European sites. While NAA is often taken to radiate $1 \mathrm{MW}$, in middle to late 2005 the transmitter was radiating about $600 \mathrm{~kW}$. The receivers are located at Cambridge, UK $\left(52.3^{\circ} \mathrm{N}, 0^{\circ} \mathrm{E}, L=2.3\right)$, Ny Ålesund, Svalbard $\left(79^{\circ} \mathrm{N}, 11^{\circ} \mathrm{E}\right.$, $\mathrm{L}=18.3)$, and Sodankylä, Finland $\left(67^{\circ} \mathrm{N}, 23^{\circ} \mathrm{E}, \mathrm{L}=5.1\right)$. These sites are part of the Antarctic-Arctic Radiation-belt Dynamic Deposition VLF Atmospheric Research Konsortia (AARDDVARK). More information on AARDDVARK can be found at the Konsortia Web site: http://www.physics. otago.ac.nz/space/AARDDVARK_homepage.htm. Figure 4 shows the location of the transmitter site (circle), the receiver sites (diamonds), and the modeling location $\left(54^{\circ} \mathrm{N}, 35^{\circ} \mathrm{W}\right.$, asterisk), and also indicates the great circle propagation paths between the transmitter and receivers. The receivers at these locations were AbsPAL (Cambridge) [Thomson et al., 2005], and OmniPAL (Ny Ålesund, Sodankylä) [Dowden et al., 1998] instruments, both of which log the amplitude and phase of the MSK modulated transmissions from NAA. The midpoints of the transmitter-receiver great circle paths are at $L \approx 3.2$ for NAA-Cambridge, $L \approx 12$ for NAA- Ny Alesund, and $L \approx 7.5$ for NAA- Sodankylä.

\subsection{Modeling Subionospheric Propagation}

[14] Mesospheric ionization effects on VLF/LF wave propagation can be modeled using the Long Wave Propagation Code (LWPC) [Ferguson and Snyder, 1990]. LWPC models VLF signal propagation from any point on Earth to any other point. Given electron density profile parameters for the upper boundary conditions, LWPC calculates the expected amplitude and phase of the VLF signal at the reception point. For undisturbed time periods, the $D$ region electron density altitude profile is often expressed through a Wait ionosphere, defined in terms of a sharpness parameter $\beta$ and a reference height $h^{\prime}$ [Wait and Spies, 1964], and the electron number density (i.e., electrons per $\mathrm{m}^{-3}$ ), $N_{e}$, increases exponentially with altitude $z$,

$N e(z)=1.43 \times 10^{13} \exp \left(-0.15 h^{\prime}\right) \times \exp \left((\beta-0.15)\left(z-h^{\prime}\right)\right)$.

For example, the amplitude of NAA at Cambridge at midday for undisturbed ionospheric conditions has been experimentally measured at $60-61 \mathrm{~dB}$ above $1 \mu \mathrm{Vm}^{-1}$. Using the daytime ionospheric model of McRae and Thomson [2000], where $\beta=0.37 \mathrm{~km}^{-1}$ and $h^{\prime}=72.5 \mathrm{~km}$, LWPC models the received amplitude of NAA at Cambridge as $60.7 \mathrm{~dB}$ above $1 \mu \mathrm{Vm}^{-1}$, showing the power of the model. The LWPC model can be used to investigate changes in the lower ionosphere as long as the induced changes to the electron density altitude-profiles are known. One approach is to provide this using the Sodankylä Ion Chemistry model (SIC, version 6.8) [Verronen et al., 2005] to determine the effects of the additional ionization caused by particle precipitation. The combination of LWPC and the SIC model to understand VLF observations has been reported in previous studies [e.g., Clilverd et al., 2005, 2006b]. The modeling of electron density changes produced by particle precipitation is described in section 4 , which also includes a full description of SIC.

\subsection{Subionospheric Observations}

[15] Figure 5 shows the NAA received amplitude (diamonds) at Ny Alesund (NYA; top panels), Sodankylä (SGO; middle panels), and Cambridge (CAM; lower panels) for midday (right panels) and midnight (left panels) conditions. Note that the experimental data is in $\mathrm{dB}$ relative to an arbitrary reference level. In all six panels, the dash-dot lines show the expected amplitudes for undisturbed conditions. The heavy black horizontal line indicates the main period where $K_{p}>6$ (10-13 September). The onset of the solar proton event shown in Figure 1 is indicated by the vertical dashed line. The solid line in the top two sets of panels is the predicted NAA amplitude modeling using a combination of LWPC and the SIC model to simulate the effect of the solar protons following the approach outlined by Clilverd et al. [2006b]. As expected the proton simulations show that the two top (high $L$-shell) receivers are strongly influenced by precipitation of protons during the solar proton event. The modeling indicates that we would not expect the proton effects to last beyond 15 September during the night and 20 September during the day, which 

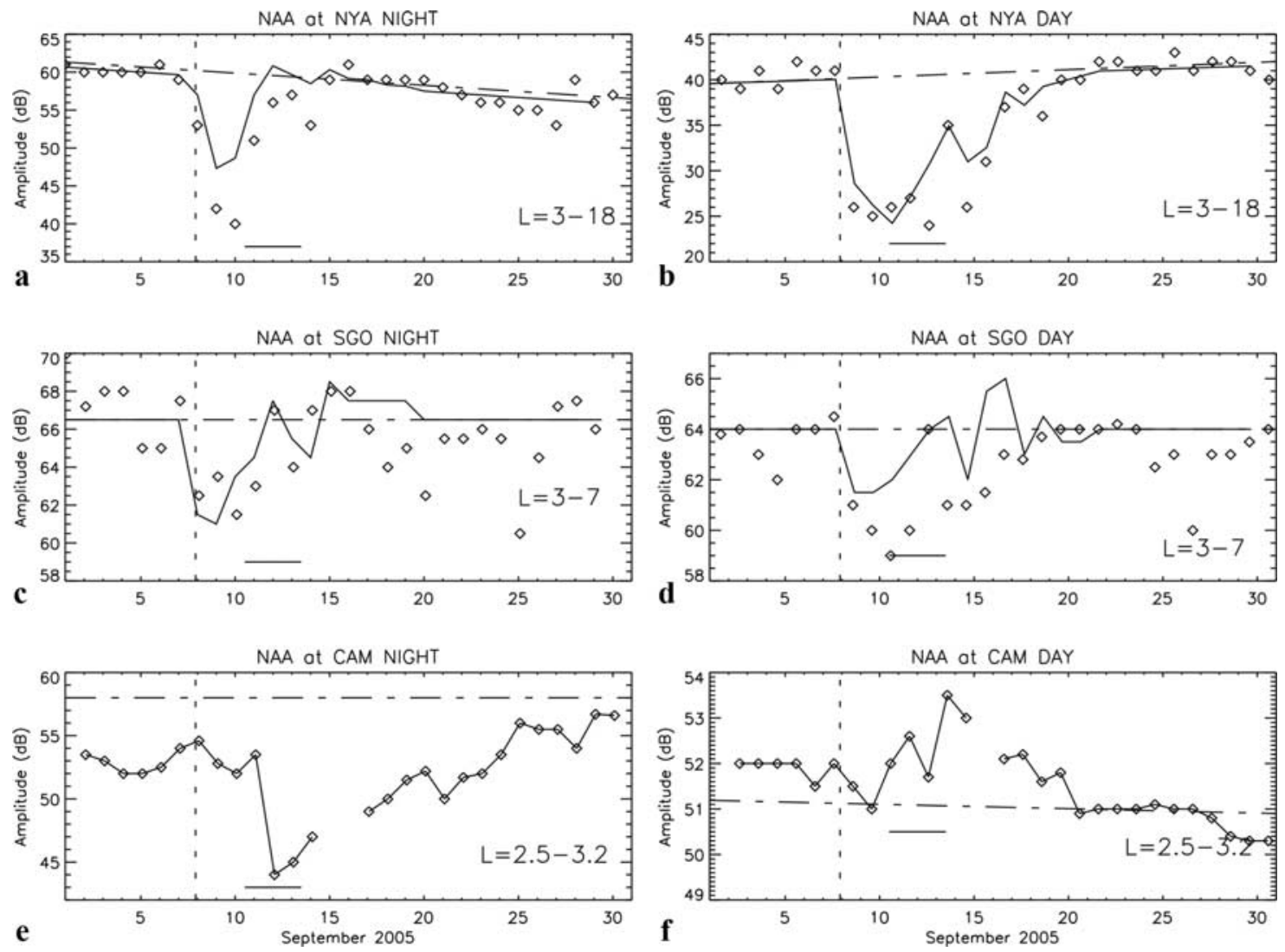

Figure 5. Received amplitudes of NAA at Ny Ålesund (NYA), Sodankylä (SGO), and Cambridge (CAM) for (right) midday and (left) midnight, with the dash-dotted lines showing the expected amplitudes for undisturbed conditions. $(a-d)$ Diamonds show the experimental data, while the line shows the simulated amplitude changes expected due to solar proton forcing. $(\mathrm{e}-\mathrm{f})$ Diamonds connected by a line show the experimental data.

is in very good agreement with the observations at $\mathrm{Ny}$ Alesund (NYA). However, the observed amplitude changes at Sodankylä (SGO) are larger and longer lived than predicted from the proton forcing modeling. In addition, there are substantial changes in the observed NAA amplitude at Cambridge, which will only be marginally impacted by protons due to rigidity cutoffs [Störmer, 1930], even taking into account the levels of geomagnetic activity [Rodger et al., 2006]. This provides strong evidence for the precipitation of energetic electrons from the radiation belts occurring at lower $L$-shells, with the path from NAA to CAM dominated by the electron precipitation.

[16] We therefore concentrate on the NAA observations from Cambridge, for which the great circle path largely passes along the $L=3.2$ contour, and so is only likely to be affected by the CRRES and DEMETER reported radiation belt flux enhancements described above. Additional evidence for this comes from the NAA to CAM observed amplitudes in early September, which indicate precipitation from the late August/early September geomagnetic storms. This is in contrast with NAA to NYA, the received amplitudes of which agree well with the expected undisturbed conditions. As shown in the lower panels of Figure 5, the ionospheric forcing from the energetic electron precipitation leads to a $2.4 \pm 0.3 \mathrm{~dB}$ increase in the amplitude of NAA observed at Cambridge at midday, but a $14 \pm 1 \mathrm{~dB}$ decrease in the same quantity observed at midnight. By modeling the time-varying amplitude changes of NAA observed at Cambridge we can determine the precipitation rate of electrons from the radiation belts along this great circle path.

\section{Ionospheric Effects of Precipitation}

[17] The ionization rate due to precipitating energetic electrons is calculated by an application of the expressions in the work of Rees [1989], expanded to higher energies based on Goldberg and Jackman [1984]. The background neutral atmosphere is calculated using the NRLMSISE-00 neutral atmospheric model [Picone et al., 2002]. The energy spectrum is taken from the fit to the CRRES observations shown in Figure 3, extrapolated over the energy range 150$3000 \mathrm{keV}$. As the precipitating flux magnitude is unknown, and the topic of our study, we consider what electron precipitation flux best reproduces our subionospheric radio wave data using the fitted energy spectrum.

\subsection{Sodankylä Ion Chemistry Model}

[18] In order to determine the impact of the energetic precipitation on the lower ionosphere, the ionization rate must be combined with a chemistry model to determine the 

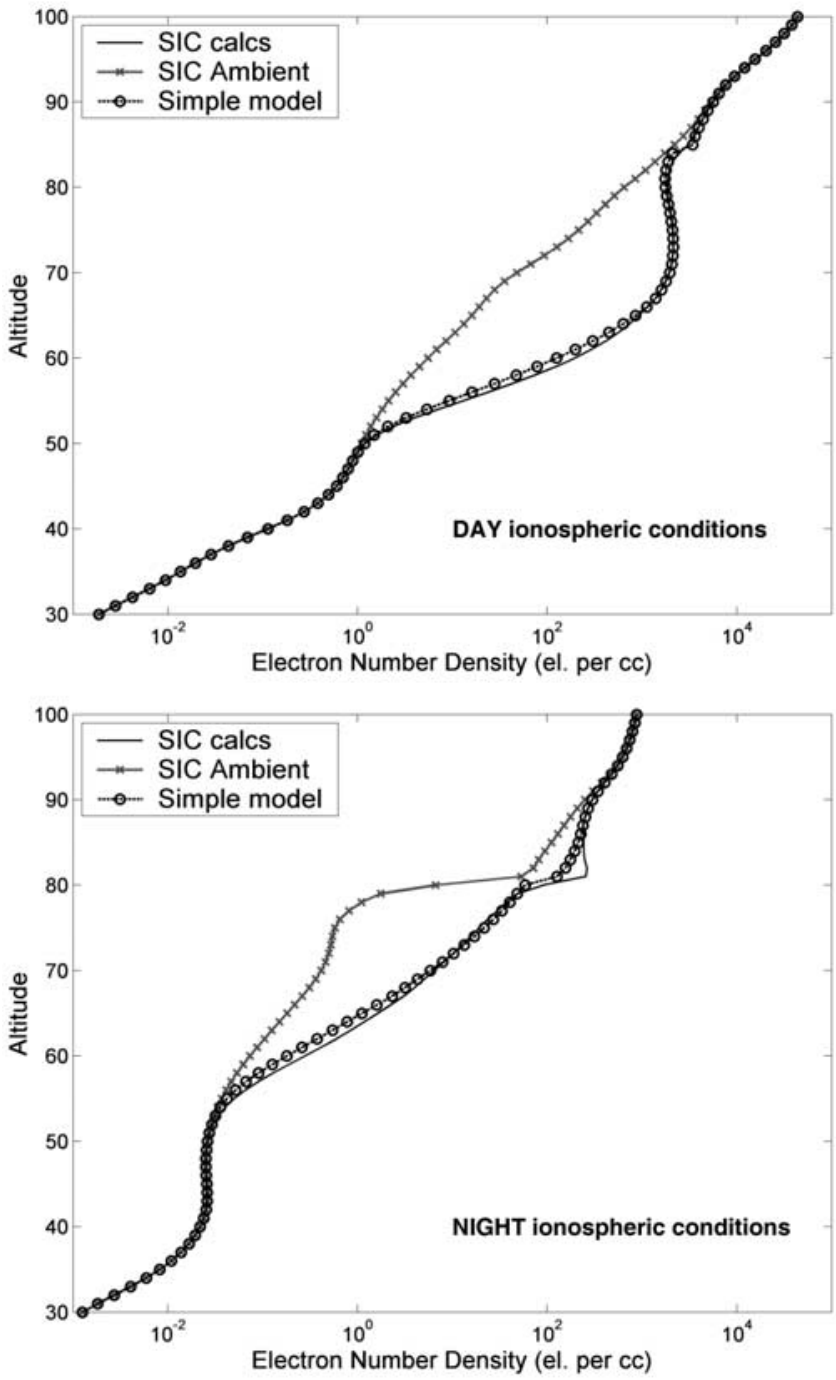

Figure 6. Electron number density profiles with altitude calculated by the SIC model for undisturbed conditions (line with crosses) and due to forcing by energetic particle precipitation (heavy line) for midday and midnight. The dotted line with circles shows the electron density profile calculated using a simple electron density model described in the text.

change in electron number density. Figure 6 shows the impact of the CRRES-described precipitating electrons on the lower ionosphere at midday (upper panel) and midnight (lower panel), calculated by the Sodankylä Ion Chemistry model (solid lines). The Sodankylä Ion Chemistry (SIC, version 6.8) model is a one-dimensional ion and neutral chemistry model designed for ionospheric $D$ region studies, solving the concentrations of 63 ions, including 27 negative ions, and 13 neutral species at altitudes across $20-150 \mathrm{~km}$. The model has recently been discussed by Verronen et al. [2005], building on original work by Turunen et al. [1996] and Verronen et al. [2002]. A detailed overview of the model was given in the work of Verronen et al. [2005], but we summarize in a similar way here to provide background for this study.
[19] In the SIC model several hundred reactions are implemented, plus additional external forcing due to solar radiation $(1-422.5 \mathrm{~nm})$, electron and proton precipitation, and galactic cosmic radiation. Initial descriptions of the model are provided by Turunen et al. [1996], with neutral species modifications described by Verronen et al. [2002]. Solar flux is calculated with the SOLAR2000 model (version 2.21) [Tobiska et al., 2000]. The scattered component of solar Lyman- $\alpha$ flux is included using the empirical approximation given by Thomas and Bowman [1986]. The SIC model includes vertical transport [Chabrillat et al., 2002] which takes into account molecular diffusion coefficients [Banks and Kockarts, 1973]. The background neutral atmosphere is calculated using the MSISE-90 model [Hedin, 1991] and tables given by Shimazaki [1984].

[20] Figure 6 shows the "ambient" electron number density profiles for midday and midnight (lines with crosses), calculated by the SIC model with no particle precipitation on 13 September 2005 at the location $\left(54^{\circ} \mathrm{N}\right.$, $35^{\circ} \mathrm{W}$ ) marked on Figure 4, that is, the half-way point on the NAA-CAM path. The SIC-calculated precipitation-modified electron number density profiles presented in this figure (solid line) represent the stable equilibrium state for the electron number density including the effect of a constant CRRES-described electron precipitation source, with a stable state reached in $<10$ min after the precipitation starts. The upper panel shows the resulting enhanced electron densities at midday created by energetic precipitation with a $>150 \mathrm{keV}$ integral flux magnitude (measured in el. $\mathrm{cm}^{-2} \mathrm{~s}^{-1}$ ) that is $4 \times 10^{-5}$ of the trapped flux reported by CRRES (Figure 4), while the lower panel shows this for midnight and a flux magnitude that is $2 \times 10^{-6}$ of the trapped flux reported by CRRES. The choice of the daytime and nighttime precipitation flux magnitudes will become apparent in section 5 .

[21] The energetic electron precipitation significantly alters the electron number density in Figure 6 over the altitude range of $\sim 55-90 \mathrm{~km}$, by $1.5-2$ orders of magnitude at $\sim 70 \mathrm{~km}$. Note that this reflects the significance of the precipitation, and not the limits of the $150-3000 \mathrm{keV}$ energy range. Precipitating $3 \mathrm{MeV}$ electrons produce ionization rates which are largest at $\sim 47 \mathrm{~km}$ altitude, which due to the spectral roll-off in population have a minor effect as seen in Figure 6. In contrast, $150 \mathrm{keV}$ electrons affect altitudes above about $\sim 80 \mathrm{~km}$. Taking the lower limit of $150 \mathrm{keV}$ does not significantly alter the electron profiles; for example, taking the lower limit as $10 \mathrm{keV}$ would lead to no change in Figure 6 for daytime conditions, and a very slight increase in electron density for nighttime altitudes above $85 \mathrm{~km}$ (not shown), too small to make a significant change in the VLF propagation conditions relative to the much more significant electron density increases at lower altitudes.

\section{2. "Simple" Ionospheric Electron Model}

[22] The full SIC model is somewhat too complex for exploring the most likely precipitation flux magnitudes with LWPC, as the computation time is relatively high. For this reason, we made use of a considerably simpler model to describe the balance of electron number density in the lower ionosphere, based on that given by Rodger et al. [1998]. In 

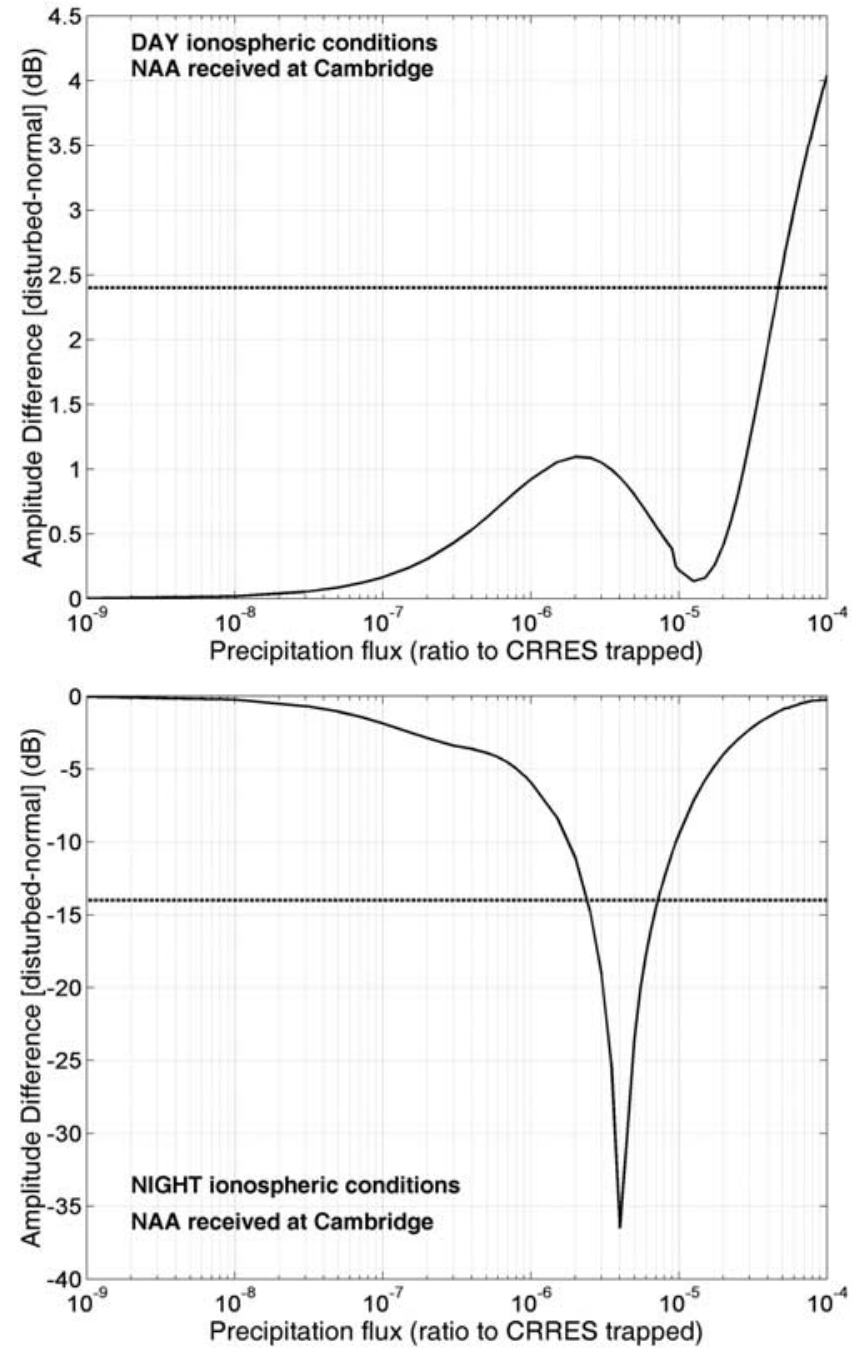

Figure 7. LWPC-modeled received amplitude changes for varying precipitation magnitudes. The horizontal dotted lines indicate the peak experimentally observed amplitude differences.

this model the evolution of the electron density in time is governed by the equation

$$
\frac{\partial N_{e}}{\partial t}=q-\beta N_{e}-\alpha N_{e}^{2}
$$

where $q$ is the ionization rate, $\alpha$ is the recombination coefficient $\left(\mathrm{m}^{3} \mathrm{~s}^{-1}\right)$, and $\beta$ is the attachment rate $\left(\mathrm{s}^{-1}\right)$. Rodger et al. [1998] provides expressions for the altitude variation of $\alpha$ and $\beta$, appropriate for nighttime conditions. A comparison of the SIC calculations with the electron number densities calculated using the Rodger expressions, for the same ionization rates, showed that the Rodger expressions provided acceptable agreement with the SIC nighttime calculations, but that the Rodger approach gave very different answers when compared with the SIC daytime calculations. However, through trial and error modified recombination and attachment coefficients have been determined which do an excellent job at reproducing both the daytime and nighttime SIC electron number densities but with much lower computational loads. Note that these expressions can only provide information on electron number densities, unlike SIC which solves the ion and neutral concentrations. A comparison between SIC and the simple model is shown in Figure 6, where the simple model is shown as a dotted line with circles.

\subsubsection{Nighttime}

[23] Small changes are made in the Rodger et al. [1998] expressions to provide the best quality agreement with SIC nighttime calculations. For altitudes above $80 \mathrm{~km}$,

$$
\alpha_{e f f}=2.5 \times 10^{-11} \sqrt{300 / T_{e}} \mathrm{~m}^{3} \mathrm{~s}^{-1}
$$

where $T_{e}$ is the electron temperature, while for altitudes of $80 \mathrm{~km}$ and below,

$$
\alpha_{e f f}=2.0 \times 10^{-12}\left(T_{e} / 300\right)^{-0.55} \mathrm{~m}^{3} \mathrm{~s}^{-1}
$$

The attachment rate in the work of Rodger et al. [1998] is described through $\beta=\beta_{1}+\beta_{2}$, where $\beta_{1}$ is defined in Table 1 of that paper, and $\beta_{2}$ in equation (22). In the modified expressions,

$$
\beta=\left(\beta_{1}+\beta_{2}\right) / 1.4
$$

\subsubsection{Daytime}

[24] The original Rodger expressions are insufficient to describe the daytime electron density levels, particularly attachment reactions which occur much more slowly due to solar input. For altitudes above $84 \mathrm{~km}$,

$$
\alpha_{e f f}=3 \times 10^{-12} \sqrt{300 / T_{e}} \mathrm{~m}^{3} \mathrm{~s}^{-1}
$$

while for altitudes of $84 \mathrm{~km}$ and below,

$$
\alpha_{\text {eff }}=5.0 \times 10^{-13}\left(T_{e} / 300\right)^{-0.55} \mathrm{~m}^{3} \mathrm{~s}^{-1}
$$

The attachment rate for daytime is best modeled by

$$
\beta=\left(\beta_{1}+\beta_{2}\right) / 75
$$

\section{Modeling the Precipitation Effect on Subionospheric Propagation}

[25] The electron number density profiles determined using the simple ionospheric electron model for varying precipitation flux magnitudes are used as input to the LWPC subionospheric propagation model, thus modeling the effect of precipitation on the NAA received amplitudes at Cambridge. An undisturbed electron density profile is used which reproduces the received NAA amplitudes at Cambridge, specified by the Wait ionosphere $\beta=0.37 \mathrm{~km}^{-1}$ and $h^{\prime}=72.5 \mathrm{~km}$ for midday and $\beta=0.5 \mathrm{~km}^{-1}$ and $h^{\prime}=85 \mathrm{~km}$ for midnight. The difference in the LWPC-modeled received amplitude changes for varying precipitation magnitudes is shown in Figure 7, for midday (top panel) and midnight (bottom panel) ionospheric conditions. The horizontal dot- 


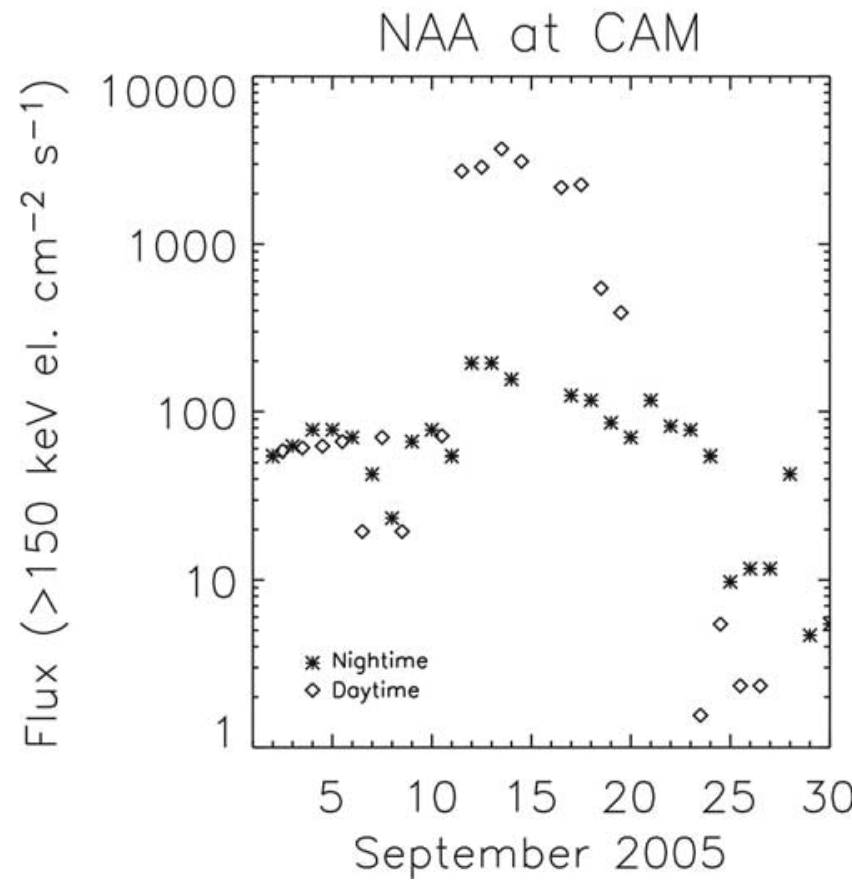

Figure 8. Time variation of the $>150 \mathrm{keV}$ electron flux precipitated into the atmosphere, determined for midday (diamonds) and midnight (asterisks) using the NAA amplitude differences received at Cambridge (Figure 5).

ted lines indicate the peak experimentally observed amplitude differences, $+2.4 \pm 0.3 \mathrm{~dB}$ at midday on 13 September 2005 and $-14 \pm 1 \mathrm{~dB}$ at midnight on 12 September 2005 . The peak experimental amplitude difference at midday is best modeled by a flux magnitude that is $\sim 4.5 \times 10^{-5}$ of the typical post-storm trapped flux reported by CRRES, while for midnight the experimental data is best modeled by a flux magnitude ratio of $\sim 2.4 \times 10^{-6}$. This equates to peak precipitated fluxes of $>150 \mathrm{keV}$ electrons of $3500 \pm 300 \mathrm{el} . \mathrm{cm}^{-2} \mathrm{~s}^{-1}$ at midday and $185 \pm 15 \mathrm{el} . \mathrm{cm}^{-2} \mathrm{~s}^{-1}$ at midnight. For both midday and midnight conditions, multiple precipitation flux levels can lead to the same amplitude difference, particularly for the midnight case, where there is a very strong modal discontinuity for flux ratios of about $4 \times 10^{-6}$. In general it should be possible to discriminate between the possible fluxes by assuming near-continuity in the dayto-day precipitation levels, although this should be confirmed by follow-on studies.

\section{Observed Precipitation From Subionospheric Propagation Measurements}

[26] Figure 8 shows the time variation of the $>150 \mathrm{keV}$ electron flux precipitated into the atmosphere, determined from the time-varying amplitude differences of NAA received at Cambridge $(L=3.2)$ shown in Figure 5 combined with the modeled response shown in Figure 7. Both daytime (diamonds) and nighttime (asterisks) precipitating fluxes are seen to increase around the start of the large geomagnetic storm on 11-12 September 2005, followed by a recovery toward undisturbed conditions over the following $10-$ 15 days. During the $6 \mathrm{~d}$ following the storm onset the midday precipitated fluxes are approximately 20 times larger than observed at midnight. This day-night precipitation flux difference is consistent with the statistical pattern of plasmaspheric hiss intensities reported around the geomagnetic equator using CRRES observations. During geomagnetically disturbed conditions $\left(\mathrm{AE}^{*}>150 \mathrm{nT}\right)$ the average plasmaspheric hiss intensity in the $0.2-0.5 \mathrm{kHz}$ band was reported to be $\sim 10$ times stronger on the dayside than the nightside, while at higher frequencies $(4-5 \mathrm{kHz})$ the waves are orders of magnitudes weaker and stronger on the nightside rather than dayside [Meredith et al., 2006b, Figure 7]. At $L=3.2,0.5 \mathrm{kHz}$ waves will undergo cyclotron resonance [Chang and Inan, 1983] with $160 \mathrm{keV}$ electrons, altering the pitch angles of the electrons and potentially driving them into the bounce loss cone such that they can precipitate into the atmosphere. Lower frequencies resonate with higher-energy electrons, representative of the $>150 \mathrm{keV}$ precipitating fluxes considered in our study, with $1 \mathrm{MeV}$ electrons resonating with waves of $\sim 40 \mathrm{~Hz}$. Thus the observed variation in the low-frequency band plasmaspheric hiss could drive the precipitation of energetic electrons, leading to the order of magnitude day-night difference in precipitation fluxes seen in Figure 8.

[27] The ICE instrument on the DEMETER spacecraft provides continuous measurements of the power spectrum of one electric field component in the VLF band [Berthelier et al., 2006]. Figure 9 shows the daily variation in the mean power spectrum over the frequency band $40-500 \mathrm{~Hz}$ for the geographic longitude range $300-360^{\circ} \mathrm{E}$ and $L=3.2$, that is, corresponding to the great circle path between NAA and Cambridge. Again, the daytime observations are represented by diamonds while those at night are shown by asterisks. Comparing Figure 8 and Figure 9 shows quite close agreement between the behavior of the $40-500 \mathrm{~Hz}$ waves in the plasmaspheric hiss band and the observed precipitating electrons. Note that both the wave power and precipitating particle fluxes vary by a factor of $\sim 200$ between

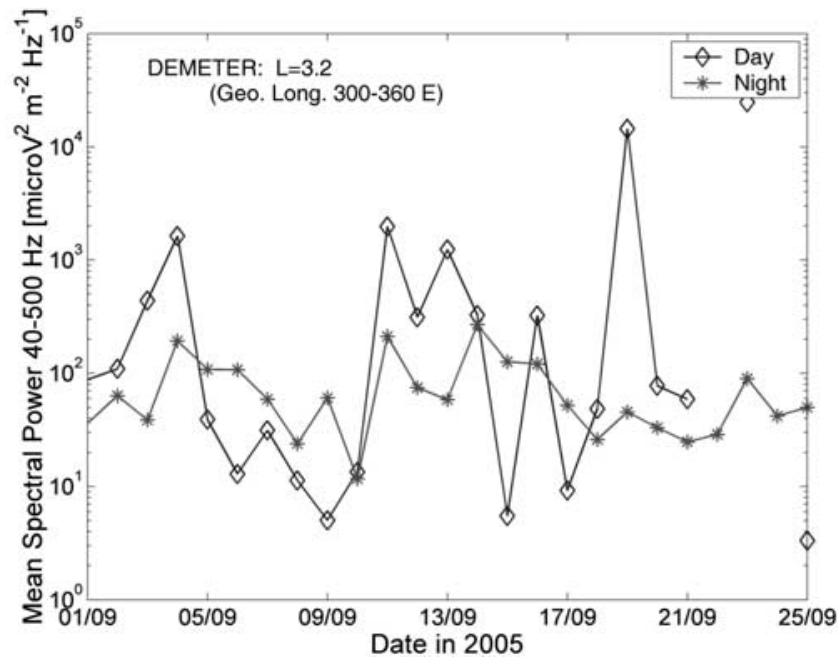

Figure 9. Time variation of the mean spectral power in the $40-500 \mathrm{~Hz}$ frequency band at $L=3.2$ and restricted to the geographic longitude range of $300-360^{\circ} \mathrm{E}$, observed by the DEMETER spacecraft for day (diamonds) and night (asterisks). 
the period 9-11 September 2005, with the daytime wave powers roughly 10 times larger than at nighttime, and with a similar ratio between day and night seen in the precipitating fluxes. In the periods where the wave power is larger by night than by day, for example 5-9 September, there is evidence for similar behavior in the precipitating particles. The primary difference between the two plots occurs before 5 September 2005 and after 20 September 2005. For the situation before 5 September 2005 large plasmaspheric hiss wave power is present, but strong increases in precipitating particle fluxes were not seen, despite the availability of particles in the radiation belts (Figure 2). In the later case the large plasmaspheric hiss wave power present in the daytime was not associated with a subionospherically measured increase in precipitation fluxes, perhaps because of a lack of particle availability. Nonetheless, this comparison provides strong evidence that plasmaspheric hiss with frequencies below $\sim 500 \mathrm{~Hz}$ is the primary driver for the loss of energetic electrons in the inner zone of the outer radiation belts during the non-storm time periods of this study period. However we acknowledge that the driver that leads to the differing precipitation fluxes we observe on the dayside and nightside is not wholly resolved, and the examination of additional similar events will be necessary to confirm the current study.

\section{Discussion}

[28] Meredith et al. [2003b] have shown that the intensities of lower-band VLF chorus, which has frequencies from a tenth to a half of the electron gyrofrequency, are also enhanced during geomagnetic disturbances. However, dawnside equatorial chorus does not reproduce the daynight differences seen in our precipitation fluxes, as it has peak intensities on the morning and evening side. In addition at $L=3.2$ the electron gyrofrequency is $26.6 \mathrm{kHz}$ such that the lower-band chorus resonant energies span $\sim 1-25 \mathrm{keV}$, much smaller than required to explain our observed precipitation range. In contrast, off-equatorial lower-band chorus is $\sim 100$ times stronger on the dayside than the nightside, considerably larger than the factor of 10 difference seen in our precipitation measurements. However, for off equatorial chorus (observed between 15 and 30 degrees off the magnetic equator and which is enhanced on the dayside) the resonant energies are much higher $\sim 250 \mathrm{keV}$ to $\sim 1 \mathrm{MeV}$. This suggests that off equatorial chorus could contribute to the loss of energetic electrons as has been previously suggested by various authors [e.g., Horne and Thorne, 2003].

[29] The position of the plasmapause plays an important role in determining what processes may be operating in a particular region at a given time. During strong magnetic activity plasmaspheric hiss is enhanced inside the plasmasphere, principally on the dayside [Meredith et al., 2004]. In contrast, enhanced whistler mode chorus waves tend to be observed outside of the plasmapause, with the equatorial and mid-latitude waves being observed principally on the dawnside and dayside, respectively [Meredith et al., 2003a]. During strong magnetic activity $\left(K_{p}^{*}>6^{-}\right)$the plasmapause can move inside of $\mathrm{L}=3.0$ [Carpenter and Anderson, 1992], where $K_{p}{ }^{*}$ is the maximum value of the $K_{p}$ index in the previous $24 \mathrm{~h}$. Thus there are some storm time intervals, notably $\sim 11-14$ and 15-16 September 2005, when our transmitter-receiver great circle path at $L \approx 3.0$ is likely to be outside of the plasmapause, at least at certain local times. During these intervals there could be a contribution from the off-equatorial (dayside) chorus [e.g., Horne and Thorne, 2003]. Using IMAGE EUV measurements taken at 2338 UT 12 September 2005 available from euv.lpl.arizona.edu/, we have confirmed that the nighttime plasmapause was at about $L=3.5$, following the approach outlined by Goldstein et al. [2003]. Thus our transmitter-receiver GCP was inside the plasmapause during the storm time of mid-11 to mid-13 September when $K_{p} \approx 6$. At the nonstorm times our transmitter-receiver GCP at $L \approx 3.0$ will be inside the plasmasphere, and as such chorus will not play a role during these times. The period of gradual decay occurring after 17 September 2005 seen in Figure 2 is thus most likely due to plasmaspheric hiss, whereas the period of decay between 11 and 17 September could be due to a combination of both hiss and chorus.

[30] The time-varying observations of electron losses from the inner zone of the outer radiation belts shown in Figure 8 will provide an important constraint to radiation belt electron acceleration and loss models currently under development [e.g., Horne et al., 2005]. In addition, the fluxes reported in this study can be used to drive atmospheric chemistry models [e.g., Verronen et al., 2005] and test the relative significance of this precipitation to neutral atmospheric chemistry.

\section{Summary}

[31] The effect of "pumping up" the radiation belts during geomagnetic storms is translated to the Earth by the loss, that is, precipitation, of highly energized electrons into the middle and upper atmosphere (30-90 km). However, direct satellite observations of energetic electrons in the bounce loss cone are very rare due to the small size of the loss cone. In this study we have analyzed ground-based subionospheric radio wave observations of the bounce loss cone during and after a geomagnetic disturbance which occurred in September 2005. After the 11 September 2005 geomagnetic storm the particle instrument onboard the DEMETER spacecraft shows that the $>150 \mathrm{keV}$ electron fluxes in the drift loss cone at $L=3.2$ increased by a factor of $\sim 1000$ above ambient conditions. The fluxes decayed to within a factor of 5 of the ambient levels over the following 14 days. The DEMETER-measured electron energy spectrum for the poststorm increase has a gradient consistent with the typical spectra observed by the CRRES spacecraft for injections into the inner zone of the outer radiation belts, despite DEMETER measuring drift loss cone fluxes and CRRES measuring fluxes trapped near the geomagnetic equator.

[32] Our subionospheric radio wave observations of the NAA transmitter received at Cambridge during this period show that there is relativistic electron precipitation into the atmosphere occurring at $L \approx 3$. This highly energetic electron precipitation leads to large changes in subionospheric amplitudes, with peak experimentally observed amplitude differences of $+2.4 \pm 0.3 \mathrm{~dB}$ at midday on 13 September 2005 and $-14 \pm 1 \mathrm{~dB}$ at midnight on 12 September 2005 . The observed energy spectra were used 
as an input to an ionospheric chemistry and subionospheric propagation model, to describe the nature of the ionospheric ionization modifications caused by the precipitating electrons. The peak precipitated fluxes of $>150 \mathrm{keV}$ electrons into the atmosphere were $3500 \pm 300 \mathrm{el} \mathrm{cm}^{-2} \mathrm{~s}^{-1}$ at midday and $185 \pm 15 \mathrm{el} \mathrm{cm}^{-2} \mathrm{~s}^{-1}$ at midnight.

[33] The combination of satellite and subionospheric measurements allowed us to determine the time-varying electron precipitation fluxes following a storm time injection into the inner edge of the outer radiation belt, providing a direct measurement of the losses from the radiation belts into the atmosphere. During the $6 \mathrm{~d}$ following the storm onset the midday precipitated fluxes are approximately 20 times larger than observed at midnight, consistent with observed day/night patterns of plasmaspheric hiss intensities. The variation in DEMETER observed wave power at $L=3.2$ in the plasmaspheric hiss band shows similar time variation to that seen in the precipitating particles. Plasmaspheric hiss with frequencies below $\sim 500 \mathrm{~Hz}$ appears to be the primary driver for the loss of energetic electrons in the inner zone of the outer radiation belts during the non-storm time periods of this study, although off-equatorial chorus waves could contribute when the plasmapause is $L<3.0$.

[34] Acknowledgments. The peak amplitude changes observed at Cambridge correspond to the birthday of our coauthor, Annika Seppälä. May her birthdays always bring us such luck! The authors would like to thank Simon Stewart and Robert McCormick, of the University of Otago, for initial software development.

[35] Zuyin Pu thanks David Nunn and another reviewer for their assistance in evaluating this paper.

\section{References}

Abel, B., and R. M. Thorne (1998), Electron scattering loss in Earth's inner magnetosphere: 2. Sensitivity to model parameters, J. Geophys. Res., 103, 2397-2407.

Baker, D. N., et al. (2004), An extreme distortion of the Van Allen belt arising from the "Hallowe'en" solar storm in 2003, Nature, 432(7019), $878-880$.

Banks, P. M., and G. Kockarts (1973), Aeronomy, vol. B, chap. 15, pp. $32-$ 63, Academic, San Diego, Calif.

Barr, R., D. L. Jones, and C. J. Rodger (2000), ELF and VLF Radio Waves, J. Atmos. Sol. Terr. Phys., 62(17-18), 1689-1718.

Berthelier, J. J., et al. (2006), ICE, The electric field experiment on DEMETER, Planet. Space Sci., 54(5), 456-471.

Brasseur, G., and S. Solomon (1986), Aeronomy of the Middle Atmosphere, 2nd ed., D. Reidel, Dordrecht, Netherlands.

Callis, L. B., D. N. Baker, M. Natarajan, J. B. Blake, R. A. Mewaldt, R. S. Selesnick, and J. R. Cummings (1996), A 2-D model simulation of downward transport of NOy into the stratosphere: Effects on the 1994 austral spring O3 and NOy, Geophys. Res. Lett., 23, 1905-1908.

Carpenter, D. L., and R. R. Anderson (1992), An ISEE/whistler model of equatorial electron density in the magnetosphere, J. Geophys. Res., 97, $1097-1108$.

Chabrillat, S., G. Kockarts, D. Fonteyn, and G. Brasseur (2002), Impact of molecular diffusion on the $\mathrm{CO}_{2}$ distribution and the temperature in the mesosphere, Geophys. Res. Lett., 29(15), 1729, doi:10.1029/2002GL015309.

Chang, H. C., and U. S. Inan (1983), Quasi-relativistic electron precipitation due to interactions with coherent VLF waves in the magnetosphere, J. Geophys. Res., 88, 318-328.

Clilverd, M. A., C. J. Rodger, T. Ulich, A. Seppälä, E. Turunen, A. Botman, and N. R. Thomson (2005), Modeling a large solar proton event in the southern polar atmosphere, J. Geophys. Res., 110, A09307, doi:10.1029/ 2004JA010922.

Clilverd, M. A., C. J. Rodger, and T. Ulich (2006a), The importance of atmospheric precipitation in storm-time relativistic electron flux drop outs, Geophys. Res. Lett., 33, L01102, doi:10.1029/2005GL024661.

Clilverd, M. A., A. Seppälä, C. J. Rodger, N. R. Thomson, P. T. Verronen, E. Turunen, T. Ulich, J. Lichtenberger, and P. Steinbach (2006b), Modeling polar ionospheric effects during the October-November 2003 solar proton events, Radio Sci., 41, RS2001, doi:10.1029/2005RS003290.
Cummer, S. A. (2000), Modeling electromagnetic propagation in the earthionosphere waveguide, IEEE Trans. Antennas Propag., 48(9), 1420-1429.

Dowden, R. L., S. F. Hardman, C. J. Rodger, and J. B. Brundell (1998), Logarithmic decay and Doppler shift of plasma associated with sprites, J. Atmos. Sol. Terr. Phys., 60, 741-753.

Elias, A. G., and M. Z. de Artigas (2003), A search for an association between the equatorial stratospheric QBO and solar UV irradiance, Geophys. Res. Lett., 30(16), 1841, doi:10.1029/2003GL017771.

Ferguson, J. A., and F. P. Snyder (1990), Computer programs for assessment of long wavelength radio communications, Tech. Doc. 1773, Natl. Ocean Syst. Cent., San Diego, Calif.

Friedel, R. H. W., G. D. Reeves, and T. Obara (2002), Relativistic electron dynamics in the inner magnetosphere-A review, J. Atmos. Sol. Terr. Phys., 64, 265-282.

Goldberg, R. A., and C. H. Jackman (1984), Nighttime auroral energy deposition in the middle atmosphere, J. Geophys. Res., 89, 5581-5596.

Goldstein, J., M. Spasojevic, P. H. Reiff, B. R. Sandel, W. T. Forrester, D. L. Gallagher, and B. W. Reinisch (2003), Identifying the plasmapause in IMAGE EUV data using IMAGE RPI in situ steep density gradients, J. Geophys. Res., 108(A4), 1147, doi:10.1029/2002JA009475.

Green, J. C., T. G. Onsager, T. P. O'Brien, and D. N. Baker (2004), Testing loss mechanisms capable of rapidly depleting relativistic electron flux in the Earth's outer radiation belt, J. Geophys. Res., 109, A12211, doi:10.1029/2004JA010579.

Haigh, J. D., M. Blackburn, and R. Day (2005), The response of tropospheric circulation to perturbations in lower-stratospheric temperature, J. Clim., 18(17), 3672-3685

Hedin, A. E. (1991), Extension of the MSIS thermospheric model into the middle and lower atmosphere, J. Geophys. Res., 96, 1159-1172.

Horne, R. B. (2002), The contribution of wave-particle interactions to electron loss and acceleration in the Earth's radiation belts during geomagnetic storms, in URSI Review of Radio Science 1999-2002, edited by W. R. Stone, pp. 801-828, John Wiley, Hoboken, N. J.

Horne, R. B., and R. M. Thorne (2003), Relativistic electron acceleration and precipitation during resonant interactions with whistler-mode chorus, Geophys. Res. Lett., 30(10), 1527, doi:10.1029/2003GL016973.

Horne, R. B., et al. (2005), Wave acceleration of electrons in the Van Allen radiation belts, Nature, 437, 227-230.

Kennel, C. F., and H. E. Petschek (1966), Limit on stably trapped particle fluxes, J. Geophys. Res., 71, 1-27.

Langematz, U., J. L. Grenfell, K. Matthes, P. Mieth, M. Kunze, B. Steil, and C. Brühl (2005), Chemical effects in 11-year solar cycle simulations with the Freie Universität Berlin Climate Middle Atmosphere Model with online chemistry (FUB-CMAM-CHEM), Geophys. Res. Lett., 32, L13803, doi:10.1029/2005GL022686.

Lauben, D. S., U. S. Inan, and T. F. Bell (2001), Precipitation of radiation belt electrons induced by obliquely propagating lightning generated whistlers, J. Geophys. Res., 106, 29,745-29,770.

Lyons, L. R., and D. J. Williams (1984), Quantitative Aspects of Magnetospheric Physics, Geophys. Astrophys. Monogr., Kluwer, Hingham, Mass. McRae, W. M., and N. R. Thomson (2000), VLF phase and amplitude: daytime ionospheric parameters, J. Atmos. Sol. Terr. Phys., 62(7), 609618

Meredith, N. P., R. M. Thorne, R. B. Horne, D. Summers, B. J. Fraser, and R. R. Anderson (2003a), Statistical analysis of relativistic electron energies for cyclotron resonance with EMIC waves observed on CRRES, J. Geophys. Res., 108(A6), 1250, doi:10.1029/2002JA009700.

Meredith, N. P., R. B. Horne, R. M. Thorne, and R. R. Anderson (2003b), Favored regions for chorus-driven electron acceleration to relativistic energies in the Earth's outer radiation belt, Geophys. Res. Lett., 30(16), 1871, doi:10.1029/2003GL017698.

Meredith, N. P., R. B. Horne, R. M. Thorne, D. Summers, and R. R. Anderson (2004), Substorm dependence of plasmaspheric hiss, J. Geophys. Res., 109, A06209, doi:10.1029/2004JA010387.

Meredith, N. P., R. B. Horne, S. A. Glauert, R. M. Thorne, D. Summers, J. M. Albert, and R. R. Anderson (2006a), Energetic outer zone electron loss timescales during low geomagnetic activity, J. Geophys. Res., 111, A05212, doi:10.1029/2005JA011516

Meredith, N. P., R. B. Horne, M. A. Clilverd, D. Horsfall, R. M. Thorne, and R. R. Anderson (2006b), Origins of plasmaspheric hiss, J. Geophys. Res., 111, A09217, doi:10.1029/2006JA011707.

Picone, J. M., A. E. Hedin, D. P. Drob, and A. C. Aikin (2002), NRLMSISE-00 empirical model of the atmosphere: Statistical comparisons and scientific issues, J. Geophys. Res., 107(A12), 1468, doi:10.1029/2002JA009430.

Rees, M. H. (1989), Physics and Chemistry of the Upper Atmosphere, Cambridge Univ. Press, Cambridge, U.K.

Reeves, G. D., et al. (2003), Acceleration and loss of relativistic electrons during geomagnetic storms, Geophys. Res. Lett., 30(10), 1529, doi:10.1029/2002GL016513. 
Rodger, C. J. (2003), Subionospheric VLF perturbations associated with lightning discharges, J. Atmos. Sol. Terr. Phys., 65, 591-606.

Rodger, C. J., O. A. Molchanov, and N. R. Thomson (1998), Relaxation of transient ionization in the lower ionosphere, J. Geophys. Res., 103, 6969-6975.

Rodger, C. J., M. A. Clilverd, P. T. Verronen, T. Ulich, M. J. Jarvis, and E. Turunen (2006), Dynamic geomagnetic rigidity cutoff variations during a solar proton event, J. Geophys. Res., 111, A04222, doi:10.1029/2005JA011395.

Rozanov, E., et al. (2005), Atmospheric response to $\mathrm{NO}_{\mathrm{y}}$ source due to energetic electron precipitation, Geophys. Res. Lett., 32, L14811, doi:10.1029/2005GL023041.

Sauvaud, J. A., T. Moreau, R. Maggiolo, J.-P. Treilhou, C. Jacquey, A. Cros, J. Coutelier, J. Rouzaud, E. Penou, and M. Gangloff (2006), Highenergy electron detection onboard DEMETER: The IDP spectrometer, description and first results on the inner belt, Planet. Space. Sci., 54(5), $502-511$.

Sharma, A. S., Y. Kamide, and G. S. Lakhina (Eds.) (2004), Disturbances in Geospace: The Storm-Substorm Relationship, Geophys. Monogr. Ser. vol. 142, AGU, Washington, D. C.

Shimazaki, T. (1984), Minor Constituents in the Middle Atmosphere, Dev. in Earth and Planet. Phys., vol. 6, D. Reidel, Dordrecht, Netherlands.

Störmer, C. (1930), Periodische elektronenbahnen im feld eines elementarmagnetron und ihre anwendung auf bruches modellversuche und auf eschenhagens elementarwellen des erdmagnetismus, Zeitschr. f. Astrophys., 1, 237-274.

Thomas, L., and M. R. Bowman (1986), A study of pre-sunrise changes in negative ions and electrons in the D-region, Ann. Geophys., 4, 219-227.

Thomson, N. R., C. J. Rodger, and M. A. Clilverd (2005), Large solar flares and their ionospheric D-region enhancements, J. Geophys. Res., 110, A06306, doi:10.1029/2005JA011008.

Thorne, R. M., and T. R. Larsen (1976), An investigation of relativistic electron precipitation events and their association with magnetic substorm activity, J. Geophys. Res., 81, 5501-5506.

Tobiska, W. K., T. Woods, F. Eparvier, R. Viereck, L. D. B. Floyd, G. Rottman, and O. R. White (2000), The SOLAR2000 empirical solar irradiance model and forecast tool, J. Atmos. Terr. Phys., 62, 1233-1250.

Tsurutani, B. T., and G. S. Lakhina (1997), Some basic concepts of waveparticle interactions in collisionless plasmas, Rev. Geophys., 35, 491501.

Turunen, E., H. Matveinen, J. Tolvanen, and H. Ranta (1996), D-region ion chemistry model, in STEP Handbook of Ionospheric Models, edited by R. W. Schunk, pp. 1-25, SCOSTEP Secr., Boulder, Colo.

Ukhorskiy, A. Y., B. J. Anderson, P. C. Brandt, and N. A. Tsyganenko (2006), Storm time evolution of the outer radiation belt: Transport and losses, J. Geophys. Res., 111, A11S03, doi:10.1029/2006JA011690.
Vampola, A. L., J. V. Osborn, and B. M. Johnson (1992), CRRES Magnetic Electron Spectrometer, J. Spacecr. Rockets, 29, 592-595.

Van Allen, J. A. (1997), Energetic particles in the Earth's external magnetic field, in Discovery of the Magnetosphere, Hist. of Geophys., vol. 7, edited by C. S. Gillmor and J. R. Spreiter, pp. 235-251, AGU, Washington, D.C.

Verronen, P. T., E. Turunen, T. Ulich, and E. Kyrölä (2002), Modelling the effects of the October 1989 solar proton event on mesospheric odd nitrogen using a detailed ion and neutral chemistry model, Ann. Geophys., 20, $1967-1976$

Verronen, P. T., A. Seppälä, M. A. Clilverd, C. J. Rodger, E. Kyrölä, C.-F. Enell, T. Ulich, and E. Turunen (2005), Diurnal variation of ozone depletion during the October-November 2003 solar proton event, J. Geophys. Res., 110, A09S32, doi:10.1029/2004JA010932.

Wait, J. R., and K. P. Spies (1964), Characteristics of the Earth-ionosphere waveguide for VLF radio waves, NBS Tech. Note 300, Nat. Inst. of Stand. and Technol., Gaithersburg, Md.

Walt, M. (1994), Introduction to Geomagnetically Trapped Radiation, Cambridge Univ. Press, Cambridge, U.K.

Walt, M. (1996), Source and loss processes for radiation belt particles, in Radiation Belts: Models and Standards, Geophys. Monogr. Ser., vol. 97, edited by J. F. Lemaire et al., pp. 1-13, AGU, Washington, D.C.

Webb, D. F., and J. H. Allen (2004), Spacecraft and ground anomalies related to the October-November 2003 solar activity, Space Weather, 2, S03008, doi:10.1029/2004SW000075.

J.-J. Berthelier, Centre d'Etudes des Environnements Terrestre et Planétaires, 4 Avenue de Neptune, Saint Maur des Fosses, France. (jeanjacques.berthelier@cetp.ipsl.fr)

M. A. Clilverd and N. P. Meredith, Physical Sciences Division, British Antarctic Survey, High Cross, Madingley Road, Cambridge CB3 0ET, UK. (m.clilverd@bas.ac.uk; nmer@bas.ac.uk)

R. J. Gamble, C. J. Rodger, and N. R. Thomson, Department of Physics, University of Otago, P.O. Box 56, Dunedin, New Zealand. (rgamble $a$ physics.otago.ac.nz; crodger@physics.otago.ac.nz; thomson@physics. otago.ac.nz)

M. Parrot, Laboratoire de Physique et Chimie de l'Environnement, 3A Avenue de la Recherche Scientifique, F-45071 Orleans Cedex 2, France. (mparrot@cnrs-orleans.fr)

J. A. Sauvaud, Centre d'Etude Spatiale des Rayonnements, 9 Avenue du Colonel Roche F-31028, Toulouse Cedex 4, France. (sauvaud@cesr.fr)

A. Seppälä, Earth Observation, Finnish Meteorological Institute, P.O. Box 503, (Vuorikatu 15 A), FIN-00101 Helsinki, Finland. (annika.seppala@ fmi.fi)

E. Turunen, Sodankylä Geophysical Observatory, Tähteläntie 62, FIN99600 Sodankylä, Finland. (esa@sgo.fi) 